Article

\title{
A Multi-Response Optimization of Thrust Forces, Torques, and the Power of Tapping Operations by Cooling Air in Reinforced and Unreinforced Polyamide PA66
}

\author{
Rosario Domingo *(1), Beatriz de Agustina and Marta M. Marín \\ Department of Construction and Manufacturing Engineering, Universidad Nacional de Educación \\ a Distancia (UNED), C/Juan del Rosal 12, Madrid E-28040, Spain; bdeagustina@ind.uned.es (B.d.A.); \\ mmarin@ind.uned.es (M.M.M.) \\ * Correspondence: rdomingo@ind.uned.es; Tel.: +34-913-986-455
}

Received: 22 January 2018; Accepted: 16 March 2018; Published: 20 March 2018

\begin{abstract}
The use of cooling air during machining is an environmentally conscious procedure, and its applicability to different processes is a research priority. We studied tapping operations, an important operation in the assembly process, using cooling air with unreinforced polyamide (PA66) and polyamide reinforced with glass fiber (PA66-GF30). These materials are widely used in industry, but their behavior with respect to tapping has not been studied. We analyze the outcomes regarding the thrust force, torque, and power at cutting speeds between 15 and $60 \mathrm{~m} / \mathrm{min}$. The experimental tests were executed using cooling air at $22{ }^{\circ} \mathrm{C}, 2^{\circ} \mathrm{C}$, and $-18{ }^{\circ} \mathrm{C}$ in dry conditions. The $\mathrm{M} 12 \times 1.75 \mathrm{~mm}$ taps were high-speed steel, with cobalt as the base material and coatings of TiN and AlCrN. To identify the more influential factors, an analysis of variance was performed, along with multi-response optimization to identify the desirability values. This optimization shows that the optimum for PA66can be found in environments close to $3{ }^{\circ} \mathrm{C}$, while the optimum for PA66-GF30 is found at the minimal temperature studied $\left(-18^{\circ} \mathrm{C}\right)$. Thus, cooling air can be considered an adequate procedure for tapping operations, to increase the sustainability of the manufacturing processes.
\end{abstract}

Keywords: sustainable manufacturing; green operation; cooling air; machining; tapping; multi-response optimization; thrust force; torque; power; polyamide

\section{Introduction}

Green operations in manufacturing are being studied with the purpose of improving the use of resources. Advances have been realized in machining processes to improve their environmental characteristics while maintaining or increasing their efficiency. Because machining processes are most commonly used in industry, great efforts are being made to find a suitable combination of efficiency and sustainability [1,2]. In this sense, dry and cooling air machining are options to avoid the use of lubricants, which have a harmful impact on the environment and are chemical exposition risks to operators. Shokrani et al. [3], in their literature review, identified various procedures used in machining by cooling air and highlighted composites, among others, as materials that are challenging to machine. Boswell [4] found that cooling air is an efficient mechanism for metal cutting, with improvements in the quality of steel workpieces and the tool life after turning. Nor-Khairusshima [5] determined that the delamination factor improved after the milling of carbon fiber reinforced plastics at $-10{ }^{\circ} \mathrm{C}$ and high cutting speeds. Lee and Lee [6] had similar realizations during the grinding of steels at $-20{ }^{\circ} \mathrm{C}$ : a low temperature decreased the forces and tool wear. Su et al. [7] found that cooling air at $-20{ }^{\circ} \mathrm{C}$ improved the results of steel milling regarding the dry machining, both in forces and 
tool life. Liu and Chou [8], using alloys of aluminum, concluded that cooling effects decrease with increasing cutting speed and feed rate. As is seen, the decreased temperature provides improved outcomes. In more radical approaches, with greater reductions in temperature, improved results were also found. Yuan et al. [9] determined that cryogenic machining with the use of cooling air requires lower cutting forces to mill metallic alloys (TiAl6V4), and achieves lower surface roughness and higher tool life than with other procedures, such as wet, dry or MQL machining. Sun et al. [10] analyzed dry machining and machining with compressed air and cryogenic compressed air at $-196{ }^{\circ} \mathrm{C}$ in a titanium alloy, and found that the thrust and cutting forces in turning operations were lower when using compressed air.

The selection of the tool also has an important influence on the results of forces [11], torques [12], and energy or power [13]. The coating of tools, which is another factor to analyze, can influence the process variables. The tapping operation is as common as it is complex in the industry, particularly when the result is an internal thread in through or blind holes for later use in assembly processes. Two important variables for tapping control are the axial force and cutting torque [14], as well as the required power as a green operation criterion [15], because this power is responsible for the energy consumption during the cutting process, and consequently emissions are generated during the process. Similar combinations of variables, including power, can be found in the literature, e.g., in the turning [16,17]. Uzun and Korkut [18] studied the tapping process in a titanium alloy under cryogenic conditions, and found that the torque was lower in a cryogenically-treated tool than in coated and uncoated tools. In tapping operations, increasing the cutting speed can increase or decrease the thrust forces [19]. The forces and torques are higher than in flooding or MQL conditions [20]. Moreover, the values of these variables are important, because they contribute to the consumption of energy during the holes' machining [21], and thus low values of force, torque, and power contribute to lower energy consumption and to the sustainability of the process.

Polyamide PA66 and reinforced polyamide with glass fiber, PA66-GF30, are materials widely used in the industry. Research on polyamide's machinability [22] has found that the addition of glass fiber influences the tool performance, and that the specific cutting force is much higher in unreinforced polyamide. Campos et al. [23] determined that an increase of spindle speeds generates an increase of cutting temperatures, which affects the responses in drilling operations. Quadrini et al. [24] found that in drilling operations in PA66-GF30, the thrust forces are strongly dependent on the cutting conditions, and that these forces never increase with increasing cutting speed and feed rate. Similar considerations were realized by Domingo et al. [25], and could be extended to torques. Although tapping operations are performed frequently in polyamide, with or without reinforcement, the material's response to tapping has not previously been studied.

Previous studies have identified cooling air machining as an environmentally-conscious technique. Some studies have focused on the effect of cooling air in dry machining, but they are devoted to the turning of steel, [4] or the milling of carbon fiber reinforced plastic [5] or steel [7]. In addition, specific and accurate predictive models have been developed for tapping processes [26], and the influence of new factors requires new experimental data. Thus, we analyze the outcomes regarding the axial or thrust force, cutting torque, and required power under various cutting conditions in tapping operations of PA66 and PA66-GF30, and under various environments in dry conditions with compressed cooling air at several temperatures. The objective is to find the more adequate temperatures, cutting speed, and tools, using multi-response surface methodology.

\section{Materials and Methods}

The methodology consisted of an experimental approach to find the data required, and a statistical approach to identify the significant factors that affect the analyzed variables. A multi-response optimization was conducted to identify the desirability values. 


\subsection{Experimental Procedure}

The experiments were executed in a machining center, Manga Tongtai TMV-510 (Tong-tai Machine and Tool Co., Ltd., Kaohsiung Hsien, Taiwan), in dry conditions and with cooling air, using a Ranque-Hilsch vortex tube, Vortec 610 (Vortec, Cincinnati, OH, USA), with a cold air outlet nozzle $9.5 \mathrm{~mm}$ in diameter at three temperatures $-22^{\circ} \mathrm{C}, 2{ }^{\circ} \mathrm{C}$, and $-18{ }^{\circ} \mathrm{C}$-and air consumption of $7.83 \times 10^{-4} \mathrm{~m}^{3} / \mathrm{s}$; the ambient temperature was $22^{\circ} \mathrm{C}$. This approach allowed the effect of cooling air in the dry machining to be determined. The vortex tube allows cold air to be produced and directed toward the cutting tool. The temperature was measured by an infrared pyrometer, Optris (Optris Infrared Sensing, Portsmouth, NH, USA). The inlet air pressure was $0.8 \mathrm{MPa}$. To maintain the material properties, the cooling air was directed toward the tool at a distance near $30 \mathrm{~mm}$ for $10 \mathrm{~min}$ before the cutting operation. The temperatures were selected because they do not affect the polyamide in its structure, and because the cutting forces can be increased at low temperatures. At and near room temperature, the results can be considered similar [27]. Note that at $22{ }^{\circ} \mathrm{C}$, the cooling air has only been used to maintain a constant temperature (room temperature) and to avoid variations throughout the tests; thus, the results obtained at this temperature can be comparable to those obtained without cooling air.

The tests were conducted under a variety of cutting conditions, particularly at cutting speeds between 15 and $60 \mathrm{~m} / \mathrm{min}$. Two tools were selected, with different coatings and with high-speed steel enriched with cobalt near $5 \%$ (HSS-E) as the base material, and with a diameter of $12 \mathrm{~mm}$ (M12 $\times 1.75)$. These taps were supplied by Guhring (Guhring KG, Albstadt, Baden-Wurtemberg, Germany). The tap profiles can be observed in Figure 1, and the tap characteristics are given in Table 1. The coating results in differences between the taps: the titanium nitride (TiN) and aluminum chromium nitride $(\mathrm{AlCrN})$ have different characteristics. The latter coating is recommended for dry machining [28]. Liew et al. [29] found that an $\mathrm{AlCrN}$ coating has a lower coefficient of friction than TiN in ambient air in a ball-on-disc test. The holes were drilled and then tapped.

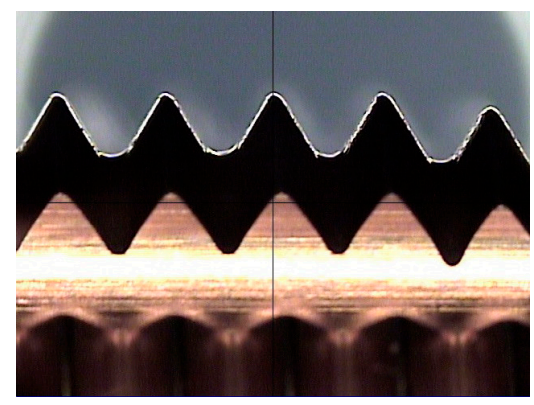

(a)

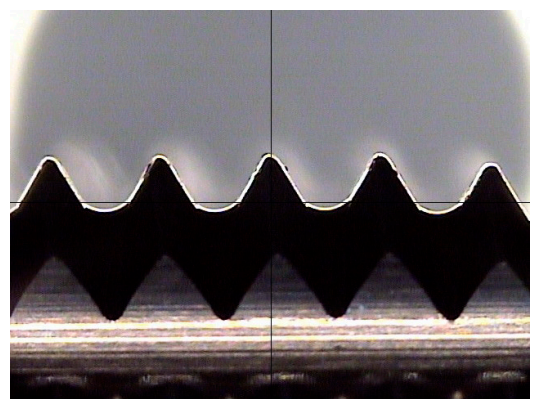

(b)

Figure 1. Tap profiles: (a) Tool T1; (b) Tool T2.

Table 1. Characteristics of tools.

\begin{tabular}{ccc}
\hline & Tool T1 & Tool T2 \\
\hline Tool material & HSS-E & HSS-E \\
Coating & TiN & AlCrN \\
Number of flutes & 5 & 5 \\
Chamfer form & $\mathrm{C}$ & $\mathrm{C}$ \\
Class of fit & $6 \mathrm{HX}$ & $6 \mathrm{HX}$ \\
\hline
\end{tabular}

The plates had a thickness of $6.5 \mathrm{~mm}$. The main mechanical and thermal properties of PA66 and PA66-GF30 are shown in Table 2. Thrust force and torque data were obtained using a Kistler dynamometer model 9257B and a Kistler multichannel amplifier model 5070A with nine channels (Kistler Group, Winterthur, Switzerland). Each measurement was taken for $0.001 \mathrm{~s}$, and DasyLab 
software (Measurement Computer, Norton, MA, USA) was used for data conversion. The average required power $(P)$ was calculated according to:

$$
P=T \times \omega
$$

where $T$ is the torque and $\omega$ is the tool rotational speed. A specific tooling was placed between the workpiece and the dynamometer to protect the latter during the tapping. Figure 2 shows a schematic diagram of experimental setup.

Table 2. Mechanical and thermal properties of PA66 and PA66-GF30.

\begin{tabular}{ccc}
\hline Properties & PA66 & PA66-GF30 \\
\hline Density $\left(\mathrm{kg} / \mathrm{m}^{3}\right)$ & 1140 & 1350 \\
Rockwell hardness M & 88 & 75 \\
Tensile strength $(\mathrm{MPa})$ & 93 & 93.1 \\
Tensile modulus $(\mathrm{GPa})$ & 3.55 & 4.65 \\
Flexural modulus $(\mathrm{GPa})$ & 3.24 & 4.48 \\
Compression strength $(\mathrm{MPa})$ & 62 & 124 \\
Thermal conductivity $(\mathrm{W} / \mathrm{m} \cdot \mathrm{K})$ & 0.280 & 0.245 \\
Coefficient of thermal expansion, linear $\left(\mu \mathrm{m} / \mathrm{m} \cdot{ }^{\circ} \mathrm{C}\right)$ & 95 & 36 \\
Melting temperature $\left({ }^{\circ} \mathrm{C}\right)$ & 260 & 260 \\
\hline
\end{tabular}

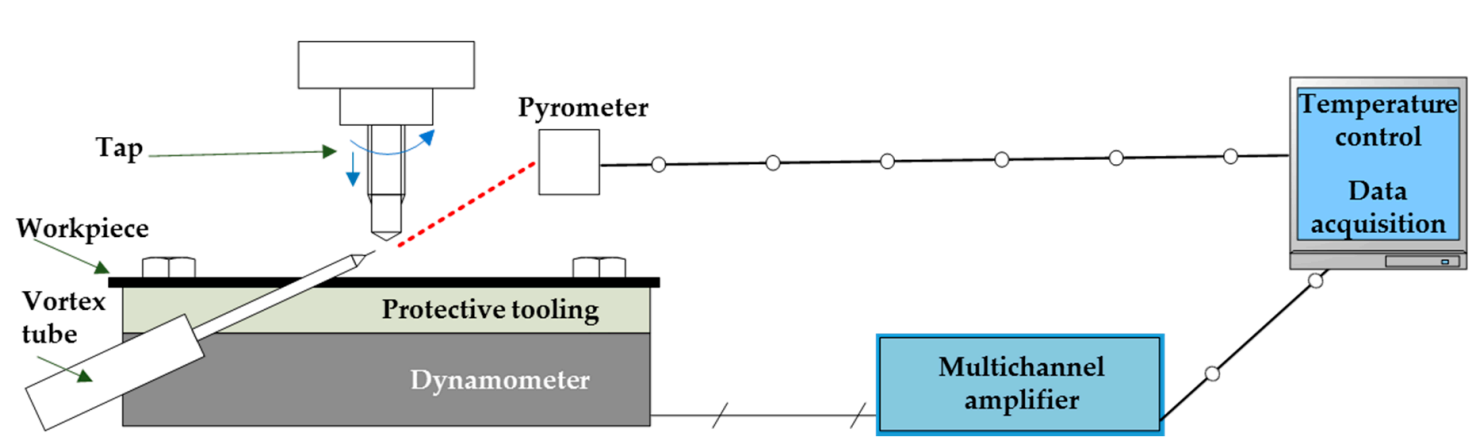

Figure 2. Scheme of experimental setup.

\subsection{Statistical Procedure}

An experimental design based on mixed-level factorial analysis was conducted using Statgraphics software (Statgraphics Technologies, Inc., The Plains, VA, USA). This design involved two numerical factors, at three and two levels, and one categorical factor at two levels, resulting in 12 tests $\left(3^{1} \times 2^{2}\right)$. The factors (environmental temperature that affects the tool, cutting speed, and coating tool) and levels (three or two, according to each factor) are shown in Table 3.

This study included a multifactorial analysis of variance (ANOVA) to determine the significant factors and interactions from a statistical perspective, at a confidence level of $95 \%$. A $p$-value less than 0.05 indicates that there are significant differences between the means of two groups of data [30]. Levels above $90 \%$ are acceptable in productive environments. Afterwards, an analysis of means (ANOM) was conducted, according to the Tukey test, to know what groups are significantly different, i.e., what levels within each factor [30].

A third-order regression model was developed for each variable. The adequacy of the regression model for each variable was determined by the coefficient of determination $\left(R^{2}\right)$ and adjusted $R^{2}$ (adj- $R^{2}$ ). $R^{2}$ indicates goodness of fit, and adj- $R^{2}$ indicates the variability of the output, and is more suitable for comparing models with different numbers of independent variables [31].

Moreover, a response surface methodology was implemented for each variable, along with a multi-response optimization to determine the desirability; this function takes values between 0 and 1 , and its optimization allows the variables to be optimized simultaneously. 
Table 3. Factors and levels.

\begin{tabular}{cccc}
\hline \multirow{2}{*}{ Factors Levels } & A & B & C \\
\cline { 2 - 4 } & Environment $\left({ }^{\circ} \mathrm{C}\right)$ & Cutting Speed $(\mathbf{m} / \mathbf{m i n})$ & Coating Tool \\
\hline 1 & Cooling at $2{ }^{\circ} \mathrm{C}$ & 15 & $\mathrm{TiN}(-1)$ \\
2 & Cooling at $2{ }^{\circ} \mathrm{C}$ & 60 & $\mathrm{AlCrN}(1)$ \\
3 & Cooling at $-18{ }^{\circ} \mathrm{C}$ & & - \\
\hline
\end{tabular}

The desirability function $(d)$ when the variables must be minimized, as in this case, is [32]

$$
d=\left\{\begin{array}{c}
0 \quad \text { if } \hat{y}_{i}>U_{i} \\
\left(\frac{U_{i}-\hat{y}_{i}}{U_{i}-L_{i}}\right)^{t} \text { if } L_{i} \leq \hat{y}_{i} \leq U_{i} \\
1 \quad \text { if } \hat{y}_{i}<L_{i}
\end{array}\right.
$$

where $\hat{y}_{i}$ is the estimated response, $U_{i}$ is the upper specification limit, $L_{i}$ is the lower specification limit, and $t$ is a weight. The global desirability $(D)$ is

$$
D=\left(\prod_{i=1}^{n} d_{i}^{r_{i}}\right)^{1 / \sum r_{i}}
$$

where $r_{i}$ is the relative importance of each variable and $n$ is the number of variables. This methodology is especially useful in manufacturing operations, because the optimization of the variables typically requires different parameter values, as can be seen in the $\mathrm{CO}_{2}$ laser-welding process [33] or in the end milling process [34]. Moreover, the methodology has a high level of interest in adapting to predict responses and optimize the process [35].

\section{Results and Discussion}

The outcomes of the experimental test can be seen in Table 4 . These results have been previously analyzed to assess which model to adopt. A third-order model was found to be the most convenient. The mixed-level factorial analysis is a screening design with resolution $\mathrm{V}$, so the factors to consider as maximum are $\mathrm{A}^{3}, \mathrm{~A}, \mathrm{~B}, \mathrm{C}, \mathrm{A}^{2}, \mathrm{~A}^{2} \mathrm{~B}, \mathrm{~A}^{2} \mathrm{C}, \mathrm{AB}, \mathrm{ABC}, \mathrm{AC}$, and $\mathrm{BC}$. In ANOVA, some factors have been eliminated to find a fitted model. In the regression equations, or the equations of the fitted models, the values of the variables are specified in their original units.

\begin{tabular}{|c|c|c|c|c|c|c|c|c|c|}
\hline \multirow[b]{2}{*}{ Test No. } & \multirow{2}{*}{$\begin{array}{c}\mathrm{A} \\
\begin{array}{c}\text { Environment } \\
\left({ }^{\circ} \mathrm{C}\right)\end{array}\end{array}$} & \multirow{2}{*}{$\begin{array}{c}\text { B } \\
\begin{array}{c}\text { Cutting Speed } \\
(\mathrm{m} / \mathrm{min})\end{array}\end{array}$} & \multirow{2}{*}{$\frac{C}{\text { Coating }}$} & \multicolumn{3}{|c|}{ PA66 } & \multicolumn{3}{|c|}{ PA66-GF30 } \\
\hline & & & & $F(\mathbf{N})$ & $\begin{array}{c}T \\
(N \cdot m)\end{array}$ & $P(W)$ & $F(\mathbf{N})$ & $\begin{array}{c}\mathrm{T} \\
(\mathrm{N} \cdot \mathrm{m})\end{array}$ & $P(W)$ \\
\hline 1 & -18 & 15 & $\mathrm{TiN}$ & 23.04 & 1.42 & 59.18 & 32.51 & 1.89 & 78.78 \\
\hline 2 & -18 & 15 & $\mathrm{AlCrN}$ & 27.22 & 1.77 & 73.77 & 22.54 & 1.67 & 69.60 \\
\hline 3 & -18 & 60 & TiN & 21.72 & 1.23 & 204.93 & 33.32 & 1.01 & 168.27 \\
\hline 4 & -18 & 60 & $\mathrm{AlCrN}$ & 27.47 & 1.72 & 286.57 & 25.77 & 1.77 & 294.90 \\
\hline 5 & 2 & 15 & $\mathrm{TiN}$ & 12.52 & 1.05 & 43.76 & 28.69 & 1.74 & 72.52 \\
\hline 6 & 2 & 15 & $\mathrm{AlCrN}$ & 19.87 & 1.25 & 52.10 & 37.78 & 1.01 & 42.09 \\
\hline 7 & 2 & 60 & $\mathrm{TiN}$ & 14.68 & 1.25 & 208.26 & 39.66 & 1.98 & 329.89 \\
\hline 8 & 2 & 60 & $\mathrm{AlCrN}$ & 22.51 & 2.27 & 378.20 & 26.37 & 1.99 & 331.55 \\
\hline 9 & 22 & 15 & TiN & 15.69 & 1.92 & 80.02 & 21.06 & 2.57 & 107.11 \\
\hline 10 & 22 & 15 & $\mathrm{AlCrN}$ & 20.76 & 2.38 & 99.19 & 32.56 & 3.10 & 129.20 \\
\hline 11 & 22 & 60 & $\mathrm{TiN}$ & 19.38 & 1.14 & 189.93 & 31.74 & 3.62 & 603.12 \\
\hline 12 & 22 & 60 & $\mathrm{AlCrN}$ & 23.01 & 1.83 & 304.89 & 22.28 & 2.37 & 394.86 \\
\hline
\end{tabular}

Table 4. Experimental results of thrust force, torque, and power. 


\subsection{Factors Affecting Thrust Force, Torque, Power, and Regression Models}

\subsubsection{Unreinforced Polyamide PA66}

As shown in Tables 5-7, the ANOVA study, which explains the variability of a variable for each effect, indicates that there are significant factors. For thrust forces (see Table 5), four main factors $\left(\mathrm{A}^{2}\right.$, $A, B$, and $C$ ) and two interactions ( $A B$ and $A^{2} C$ ) at a $95 \%$ confidence level are associated with $p$-values of less than 0.05 . The most influential factors are $\mathrm{A}^{2}, \mathrm{C}$, and $\mathrm{A}$; the environment as second-order factor $\left(\mathrm{A}^{2}\right)$ is responsible of $27.25 \%$ of the variability, while $C$ and $A$ represent variability close to $25 \%$ and $23 \%$, respectively. The residual values represent only $0.01 \%$. The strong dependency of the force regarding $\mathrm{A}$ and $\mathrm{A}^{2}$ confirms the importance of analyzing the tool temperature in the tapping and its influence.

The torque, T_PA66, has three significant factors: $A^{2} B, B$, and C (see Table 6). In this particular case, the coating had an influence of $39.31 \%$, an $\mathrm{A}^{2} \mathrm{~B}$ of $30.67 \%$, and a cutting speed of $17.04 \%$; thus, these factors had the most influence on the torque. The influence of residual values fell to $4.06 \%$.

For the power, P_PA66, there are four significant factors: $A^{2} B, B, B C$, and C (see Table 7). As expected, the most influential factor was B (42.25\%), due to the dependence of power on speed. Note that the residual values only represented $1.11 \%$. In this sense, the interaction was between environment and speed and between speed and coating, and the importance of coating can be appreciated; this finding implies a satisfactory choice of coating in the experimental test.

Table 5. Analysis of variance (ANOVA) for F_PA66.

\begin{tabular}{cccccc}
\hline Source & Sum of Squares & Df & Mean Square & F-Ratio & $p$-Value \\
\hline A: environment & 53.0965 & 1 & 53.0965 & 1849.78 & 0.0148 \\
B: cutting speed & 5.76 & 1 & 5.76 & 200.67 & 0.0449 \\
C: coating & 57.6081 & 1 & 57.6081 & 2006.96 & 0.0142 \\
A $^{2}$ & 63.7982 & 1 & 63.7982 & 2222.61 & 0.0135 \\
AB & 6.14251 & 1 & 6.14251 & 213.99 & 0.0435 \\
AC & 0.189112 & 1 & 0.189112 & 6.59 & 0.2365 \\
BC & 0.0310083 & 1 & 0.0310083 & 1.08 & 0.4877 \\
A ${ }^{2}$ & 0.932204 & 1 & 0.932204 & 32.48 & 0.1106 \\
A ${ }^{2}$ ABC & 5.73304 & 1 & 5.73304 & 199.73 & 0.0450 \\
ABdual & 1.13251 & 1 & 1.13251 & 39.45 & 0.1005 \\
Total (adj.) & 0.0287042 & 1 & 0.0287042 & & \\
\hline
\end{tabular}

Table 6. ANOVA for T_PA66.

\begin{tabular}{cccccc}
\hline Source & Sum of Squares & Df & Mean Square & F-Ratio & $p$-Value \\
\hline A: environment & 0.159613 & 1 & 0.159613 & 7.20 & 0.0550 \\
B: cutting speed & 0.3721 & 1 & 0.3721 & 16.79 & 0.0149 \\
C: coating & 0.858675 & 1 & 0.858675 & 38.74 & 0.0034 \\
A $^{2}$ & 0.130537 & 1 & 0.130537 & 5.89 & 0.0722 \\
AB & 0.148512 & 1 & 0.148512 & 6.70 & 0.0608 \\
BC & 0.118008 & 1 & 0.118008 & 5.32 & 0.0823 \\
A 2 B & 0.670004 & 1 & 0.670004 & 30.23 & 0.0053 \\
Residual & 0.0886667 & 4 & 0.0221667 & & \\
Total (adj.) & 2.18423 & 11 & & & \\
\hline
\end{tabular}

Table 7. ANOVA for P_PA66.

\begin{tabular}{cccccc}
\hline Source & Sum of Squares & Df & Mean Square & F-Ratio & $\boldsymbol{p}$-Value \\
\hline A: environment & 307.272 & 1 & 307.272 & 0.78 & 0.4282 \\
B: cutting speed & 60172.1 & 1 & 60172.1 & 151.88 & 0.0002 \\
C: coating & 7945.94 & 1 & 7945.94 & 20.06 & 0.0110 \\
A $^{2}$ & 182.381 & 1 & 182.381 & 0.46 & 0.5347 \\
\hline
\end{tabular}


Table 7. Cont.

\begin{tabular}{cccccc}
\hline Source & Sum of Squares & Df & Mean Square & F-Ratio & $p$-Value \\
\hline BC & 8771.78 & 1 & 8771.78 & 22.14 & 0.0093 \\
$\mathrm{~A}^{2} \mathrm{~B}$ & 3928.07 & 1 & 3928.07 & 9.91 & 0.0346 \\
$\mathrm{~A}^{2} \mathrm{C}$ & 663.602 & 1 & 663.602 & 1.67 & 0.2653 \\
Residual & 1584.75 & 4 & 396.188 & & \\
Total (adj.) & 142409.0 & 11 & & & \\
\hline
\end{tabular}

The ANOM study identified significant differences between the means of all levels of each factor for variables F_PA66, T_PA66, and P_PA66, at a 95\% confidence level. This could indicate that the levels have been chosen appropriately, and that there is no particularly sensitive level affecting the results, so the following analysis is necessary.

A regression model was developed for thrust forces, torque and power. With respect to thrust forces of PA66, initially, a third-order model provides an $R^{2}$ value of $99.99 \%$ and an adj- $R^{2}$ value of 99.86, which implies that this model can be considered acceptable. Close values of $R^{2}$ and adj- $R^{2}$ indicate that the significant terms are included in the model [31]. Therefore, this thrust force model in terms of multiple regression can be considered adequate, because adj- $R^{2}$ is between 0.8 and 1 [31].

The torque analysis provides an $\mathrm{R}^{2}$ value of $95.94 \%$ and adj- $\mathrm{R}^{2}$ of $88.84 \%$. To achieve a more closely fitted model, it was necessary to eliminate several factors, such as $\mathrm{A}^{2} \mathrm{C}, \mathrm{ABC}$, and $\mathrm{AC}$.

In power, the $\mathrm{R}^{2}$ statistic indicates that the model as fitted explains $98.89 \%$ of the variability in P_PA66. The adj- $R^{2}$ statistic, which is more suitable for comparing models with different numbers of independent variables, is $96.94 \%$. The regression model shows accurate capability for the third-order approach. The environment temperature $\left({ }^{\circ} \mathrm{C}\right)$ can be a determinant factor in the results obtained in $F$, $T$ and $P$.

The equations of the fitted model are:

For $\mathrm{C}=\mathrm{TiN}$,

$$
\begin{gathered}
F \_P A 66=12.21-0.26 \times A+0.05 \times B+0.01 \times A^{2}+0.002 \times A B \\
\text { T_PA66 }=0.92+0.014 \times B+0.000001 \times A^{2} B \\
\text { P_PA66 }=-39.57-0.16 \times A+5.46 \times B+0.005 \times A B
\end{gathered}
$$

For $\mathrm{C}=\mathrm{AlCrN}$,

$$
\begin{gathered}
F \_P A 66=19.51-0.26 \times A+0.05 \times B+0.01 \times A^{2}+0.002 \times A B \\
\text { T_PA66 }=1.02+0.014 \times B+0.000001 \times A^{2} B \\
\text { P_PA66 }=-40.87+0.16 \times A+5.46 \times B+0.005 \times A B
\end{gathered}
$$

\subsubsection{Reinforced Polyamide PA66-GF30}

In the ANOVA study, for axial forces (see Table 8), a second-order main factor $\mathrm{A}^{2}$ and three interactions $(A C, B C$, and $A B C$ ) are significant, because the $p$-value is less than 0.05 at the $95 \%$ confidence level. $\mathrm{BC}$ was the most influential factor (34.37\%). To achieve an acceptable value for adj- $\mathrm{R}^{2}$, several factors were eliminated: $A^{3}, A^{2} B, A^{2} C, A B$, and $B$. Thus, $R^{2}$ was $91.40 \%$, adj- $R^{2}$ was $81.09 \%$, and adj- $R^{2}$ was close to $80 \%$, so it can be considered suitable in machining processes [36].

Table 9 describes the ANOVA results for torques; at a confidence level of $95 \%$, there are two significant factors, $\mathrm{A}$ and $\mathrm{A}^{2}$, and a significant interaction $\mathrm{ABC}$. Note that the effect of environment was very strong (54.8\%). The residuals values achieved $7.77 \%$. To achieve adequate $R^{2}$ and adj- $R^{2}$, the factors $\mathrm{A}^{3}, \mathrm{~A}^{2} \mathrm{C}, \mathrm{AB}, \mathrm{BC}$, and $\mathrm{C}$ had been eliminated. For the other factors, $\mathrm{R}^{2}$ took a value of $92.23 \%$, and adj- $\mathrm{R}^{2}$ was $83 \%$. 
With respect to the power, Table 10 shows the results of the ANOVA study. Factors $\mathrm{A}^{3}$ and $\mathrm{A}^{2} \mathrm{C}$ had been eliminated to achieve a major correlation. Two main factors ( $\mathrm{A}$ and $\mathrm{B}$ ) and three interactions $(\mathrm{AB}, \mathrm{AC}$, and $\mathrm{ABC})$ have a significant effect on the results. The influence of cutting speed was higher, at $22.17 \%$ over the total. Regarding the power, its strong dependency on cutting speed was shown as a factor through interactions with the environment, as well as with the environment and coating. Therefore, the effect on power depends on variations of speed, together with the environment for each coating. Note that $\mathrm{A}^{2}$ was not a significant factor in this case. The coating affected only the interactions of the first and second order. Note that the residual represents only the $0.31 \%$. The adjustment provided an $R^{2}$ of $99.68 \%$ and an adj- $R^{2}$ of $98.23 \%$.

On the same manner as in the PA66 material, for PA66-GF30, the ANOM study identified significant differences between the means of all the levels of each factor for the variables $F, T$, and $P$, at a $95 \%$ confidence level. The same considerations above could be taken into account.

Table 8. ANOVA for F_PA66-GF30.

\begin{tabular}{cccccc}
\hline Source & Sum of Squares & Df & Mean Square & F-Ratio & $p$-Value \\
\hline A: environment & 5.28125 & 1 & 5.28125 & 0.760 & 0.4242 \\
C: coating & 32.2752 & 1 & 32.2752 & 4.62 & 0.0842 \\
A $^{2}$ & 77.832 & 1 & 77.832 & 11.15 & 0.0206 \\
AC & 47.8242 & 1 & 47.8242 & 6.85 & 0.0472 \\
BC & 139.537 & 1 & 139.537 & 19.99 & 0.0066 \\
ABC & 68.328 & 1 & 68.328 & 9.79 & 0.0260 \\
Residual & 34.9027 & 5 & 6.98055 & & \\
Total (adj.) & 405.981 & 11 & & & \\
\hline
\end{tabular}

Table 9. ANOVA for T_PA66-GF30.

\begin{tabular}{cccccc}
\hline Source & Sum of Squares & Df & Mean Square & F-Ratio & $p$-Value \\
\hline A: environment & 3.5378 & 1 & 3.5378 & 35.25 & 0.0019 \\
B: cutting speed & 0.3721 & 1 & 0.3721 & 3.71 & 0.1121 \\
A $^{2}$ & 0.8664 & 1 & 0.8664 & 8.63 & 0.0323 \\
AC & 0.19845 & 1 & 0.19845 & 1.98 & 0.2187 \\
A $^{2}$ B & 0.350417 & 1 & 0.350417 & 3.49 & 0.1206 \\
ABC & 0.9522 & 1 & 0.9522 & 9.49 & 0.0275 \\
Residual & 0.5018 & 5 & 0.10036 & & \\
Total (adj.) & 6.4552 & 11 & & & \\
\hline
\end{tabular}

Table 10. ANOVA for P_PA66-GF30.

\begin{tabular}{cccccc}
\hline Source & Sum of Squares & Df & Mean Square & F-Ratio & $p$-Value \\
\hline A: environment & $48,475.6$ & 1 & $48,475.6$ & 91.91 & 0.0107 \\
B: cutting speed & $74,755.8$ & 1 & $74,755.8$ & 141.73 & 0.0070 \\
C: coating & 798.025 & 1 & 798.025 & 1.50 & 0.3451 \\
A $^{2}$ & 3595.13 & 1 & 3595.13 & 6.82 & 0.1207 \\
AB & $24,962.7$ & 1 & $24,962.7$ & 47.33 & 0.0205 \\
AC & $11,523.1$ & 1 & $11,523.1$ & 21.85 & 0.0429 \\
BC & 325.0 & 1 & 325.0 & 0.62 & 0.5147 \\
A 2 B & 12.3267 & 1 & 12.3267 & 0.02 & 0.8925 \\
ABC & $16,759.15$ & 1 & $16,759.15$ & 31.77 & 0.0301 \\
Residual & 1054.88 & 2 & 527.438 & & \\
Total (adj.) & $337,207.0$ & 11 & & & \\
\hline
\end{tabular}

The equations of the fitted model of the force, torque, and power are:

For $\mathrm{C}=\mathrm{TiN}$,

$$
\text { F_PA66 GF30 }=33.15-0.37 \times A+0.14 \times B+0.006 \times A B-0.01 \times A^{2}
$$




$$
\begin{gathered}
\text { T_PA66 GF30 }=1.12+0.02 \times A+0.003 \times A^{2}+0.0008 \times A B \\
P \_P A 66 \text { GF30 }=-31.9-3.12 \times A+5.83 \times B+0.22 \times A B
\end{gathered}
$$

For $\mathrm{C}=\mathrm{AlCrN}$,

$$
\begin{gathered}
\text { F_PA66 GF30 }=33.15+0.37 \times A-0.14 \times B-0.006 \times A B-0.01 \times A^{2} \\
\text { T_PA66 GF30 }=1.12+0.02 \times A+0.003 \times A^{2}-0.0008 \times A B \\
\text { P_PA66 GF30 }=-31.9+0.8 \times A+5.83 \times B+0.02 \times A B
\end{gathered}
$$

\subsection{Response Surfaces}

Figure 3 shows the estimated response surface in the variables $F, T$ and $P$ in tapping operations of PA66. The effect of the coating is unambiguous, as is seen in Figure 3a-f. At environmental temperature, the thrust forces practically do not vary (Figure $3 a, b$ ), but the effect of the cutting speed is greater when the temperature drops. The coating has a determining effect on the torque; the cooling air gives a minimum at temperatures close to $0{ }^{\circ} \mathrm{C}$ with TiN (Figure 3c), while it has almost no influence with the use of AlCrN (Figure 3). With regards to power, the cooling effect is similar with both coatings, although with a greater influence on cutting speed when using AlCrN (Figure 3e,f).

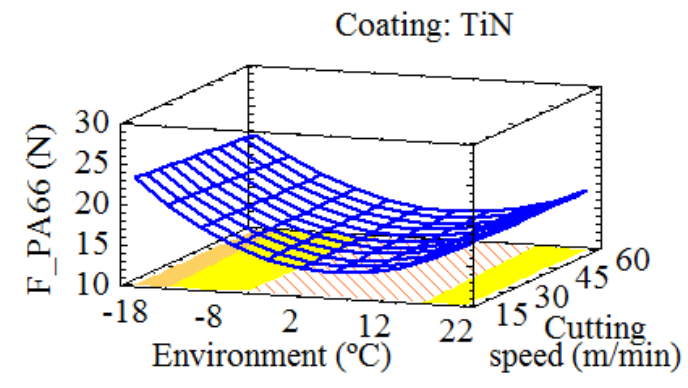

(a)

Coating: TiN

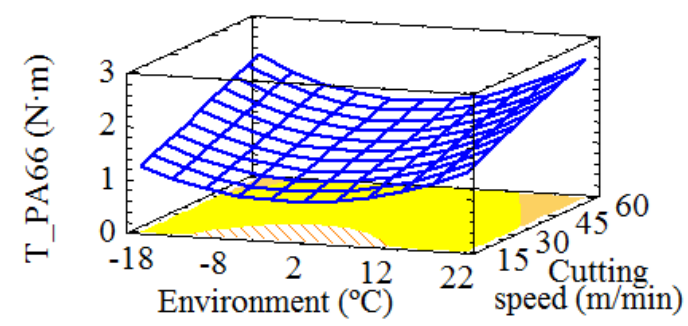

(c)

Coating: TiN

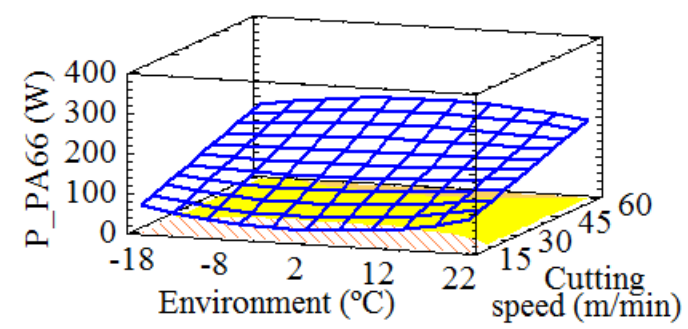

(e)

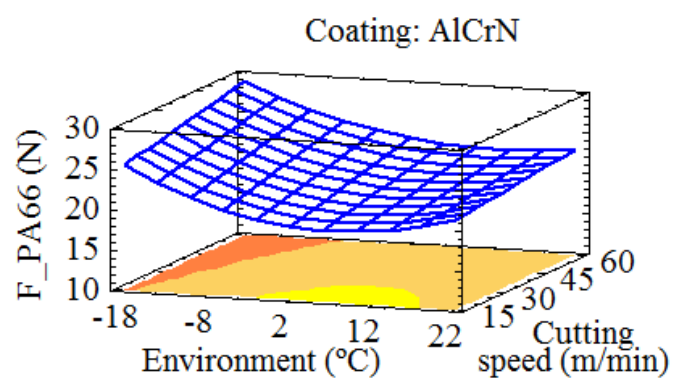

(b)

Coating: $\mathrm{AlCrN}$

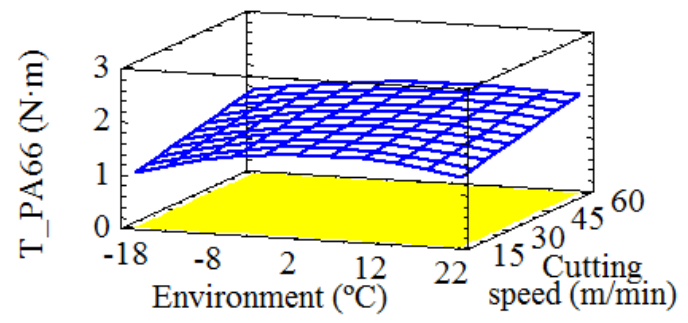

(d)

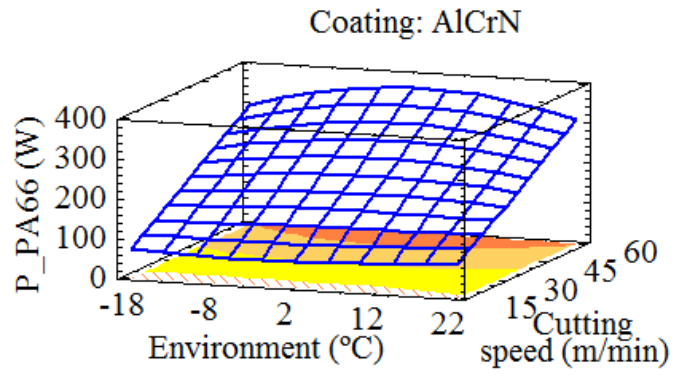

(f)

Figure 3. Estimated response surfaces for PA66: (a) forces of tapping with T1; (b) torques of tapping with T2; (c) torques of tapping with T1; (d) torques of tapping with T2; (e) power of tapping with T1; (f) power of tapping with T2. 
For PA66-GF30, Figure 4 shows the estimated response surface. These results indicate dissimilar behavior with each tool, as was expected. For high speeds, the effect of the AlCrN coating was milder. With tool T1, the thrust force increased with increasing cutting speed (Figure 4a). However, for tool T2, the thrust force decreased when the speed is increased (Figure $4 \mathrm{~b}$ ); this phenomenon is common in other materials, such as steel [19].

For each coating, in general, a reduction of torques (Figure 4c,d) and power (Figure 4e,f) could be achieved when the environmental temperature was lower, although with a strong influence of speed. This can explain the effect of the interaction ABC.

In the range of cutting conditions, with the tapping operations of the PA66-GF30 material, a coating of $\mathrm{AlCrN}$ resulted in a decrease in the thrust forces when the cutting speed was increased.

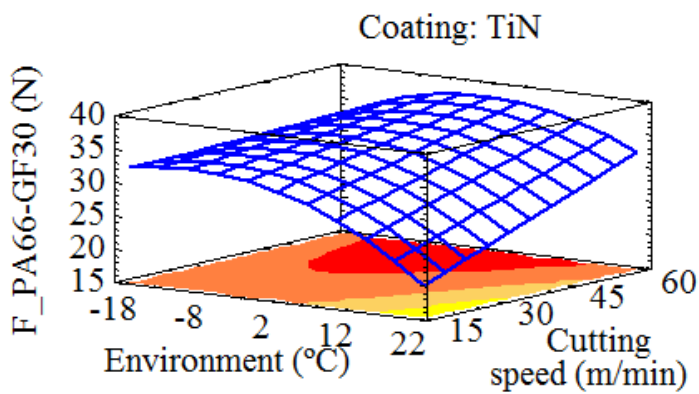

(a)



(c)

Coating: TiN

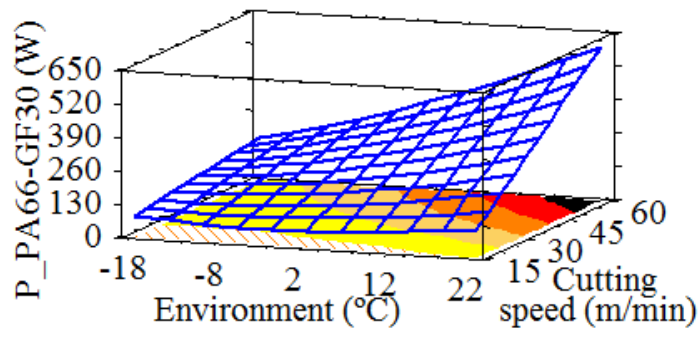

(e)



(b)

Coating: $\mathrm{AlCrN}$

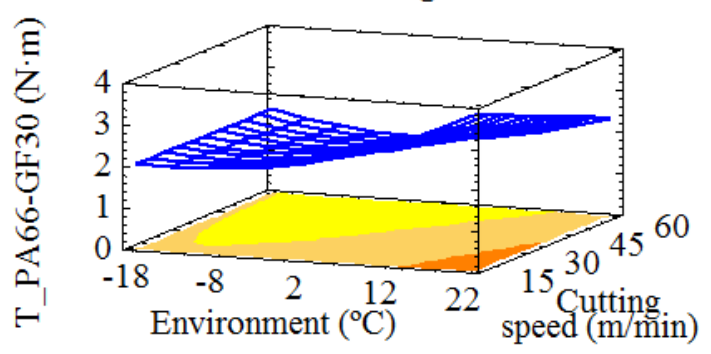

(d)

Coating: AlCrN

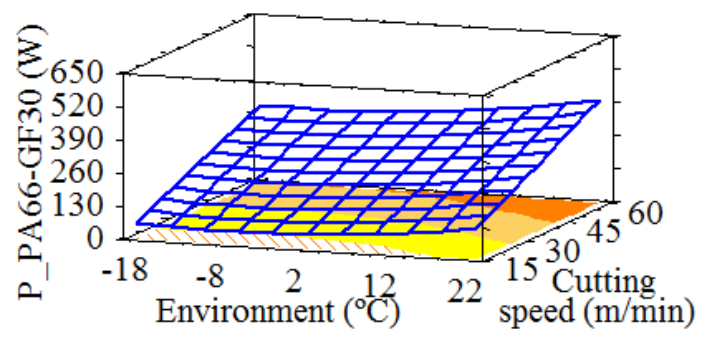

(f)

Figure 4. Estimated response surfaces for PA66-GF30: (a) forces of tapping with T1; (b) torques of tapping with T2; (c) torques of tapping with T1; (d) torques of tapping with T2; (e) power of tapping with $\mathrm{T} 1$; (f) power of tapping with $\mathrm{T} 2$.

\subsection{Multi-Response Optimization}

The goals of optimizing the response are to minimize all variables and identify each one's optimal value. In Table 11, the optimal values of each variable can be observed. First, for PA66, the importance of TiN coating can be observed; this is the coating that provides the optimal result for the three variables. However, with respect to the environment and cutting speed, several contradictions are found, as shown in Figure 3. 
Table 11. Combination of factor levels that minimize F_PA66, T_PA66, P_PA66, F_PA66-GF30, T_PA66-GF30, and P_PA66-GF30, and maximize the desirability.

\begin{tabular}{ccccccc}
\hline Optimal Values & F_PA66 & T_PA66 & P_PA66 & F_PA66-GF30 & T_PA66-GF30 & P_PA66-GF30 \\
\hline Environment $\left({ }^{\circ} \mathrm{C}\right)$ & 6.88 & -2.27 & -5.25 & 22.0 & -18.0 & -5.7 \\
Cutting speed $(\mathrm{m} / \mathrm{min})$ & 15.1 & 15.01 & 16.98 & 15.0 & 60.0 & 15.0 \\
Coating & $\mathrm{TiN}$ & $\mathrm{TiN}$ & $\mathrm{TiN}$ & $\mathrm{TiN}$ & $\mathrm{TiN}$ & $\mathrm{AlCrN}$ \\
Optimal value & $11.99 \mathrm{~N}$ & $0.99 \mathrm{~N} \cdot \mathrm{m}$ & $42.62 \mathrm{~W}$ & $19.77 \mathrm{~N}$ & $1.02 \mathrm{~N} \cdot \mathrm{m}$ & $48.68 \mathrm{~W}$ \\
Desirability $(d)$ & 1 & 1 & 1 & 1 & 0.99 & 0.99 \\
\hline
\end{tabular}

The optimal values for $F, T$, and $P$ can be obtained with different cutting and environmental conditions; only the coating is maintained in PA66. Thus, to achieve a global solution, multi-response optimization is conducted for $F, T$, and $P$ and for PA66 and PA66-GF30.

\subsubsection{Multi-Response Optimization for PA66}

This procedure helps determine the combination of experimental factors that simultaneously optimize several responses by minimizing $F, T$ and $P$, and by maximizing a desirability function. The values of weights $(t)$ are 1 for all variables, and the importance or impact $\left(r_{i}\right)$ is 3 for all variables in the two materials, as well as in the range analyzed that corresponds to the value, identified in Table 4. The current goal for each of the responses (variables) is to minimize the force, torque, and power. As shown in Figure 3, the cutting conditions that provide the minimal force, torque, and power for PA66 are different; only the TiN coating is recommended for the three variables. The temperatures are practically equal in $T$ and $P$, as is the cutting speed in $F$ and $P$ (despite the strong dependence of the power on the torque). The multiple performance gives a common optimization, according to the combination of factor levels that maximize the overall optimal desirability over the indicated region. The evolution of the desirability function is shown in Figure 5.

Finally, this optimum can be found using cooling air at temperatures near $3{ }^{\circ} \mathrm{C}\left(3.15^{\circ} \mathrm{C}\right)$, a cutting speed of $15 \mathrm{~m} / \mathrm{min}$, and a TiN coating. Consequently, the cooling air has a positive influence, although it is not necessary to achieve temperatures under zero. The TiN coating is the reference, as expected, because it is the better coating in the sub-optimization; a possible explanation is that although TiN is less lubricous than $\mathrm{AlCrN}$, and has a higher coefficient of friction than $\mathrm{AlCrN}$ [29], the required forces are low and the friction has no affect. The optimal responses for F_PA66, T_PA66, and P_PA66 are $12.26 \mathrm{~N}, 1 \mathrm{~N} \cdot \mathrm{m}$, and $30.9 \mathrm{~W}$, respectively. The optimal value of desirability $(D)$ is 0.99 .

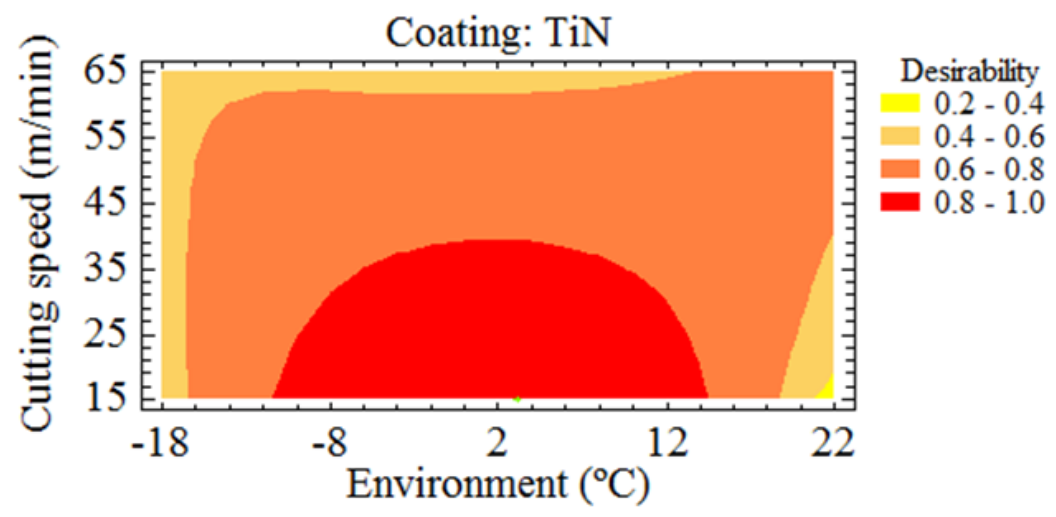

Figure 5. PA66: contours of the estimated response surface for the TiN coating.

\subsubsection{Multi-Response Optimization for PA66-GF30}

With respect to PA66-GF30, the optimization of each variable does not allow all variables to be optimized, because the values of parameters are different for each variable, as observed in Table 11. 
Thus, the multi-response optimization allows the optimal combination of cutting conditions to obtain the optimal desirability. The cooling is effective, and the minimal temperature achieved $\left(-18^{\circ} \mathrm{C}\right)$ allows a strong desirability value. The low cutting speed $(15 \mathrm{~m} / \mathrm{min})$ can be explained by its high influence on the power; the AlCrN coating is better for achieving the maximal desirability, which is notable because this coating has favorable properties for use in dry machining [28]. This coating is more lubricous than TiN [29] — AlCrN is dense and has few microvoids and microdroplets, which provides a uniform structure [37]. This uniform structure can benefit the machining process in a composite material such as PA66-GF30. Figure 6 shows the contours of the estimated response surface for the AlCrN coating.

The optimal response is $24.94 \mathrm{~N}$ for F_PA66-GF30, $1.45 \mathrm{~N} \cdot \mathrm{m}$ for T_PA66-GF30, and $63.45 \mathrm{~W}$ for P_PA66-GF30. The optimal value of desirability $(D)$ is 0.83 , which is lower than that for PA66, while the values of $F, T$, and $P$ are higher than in unreinforced polyamide.

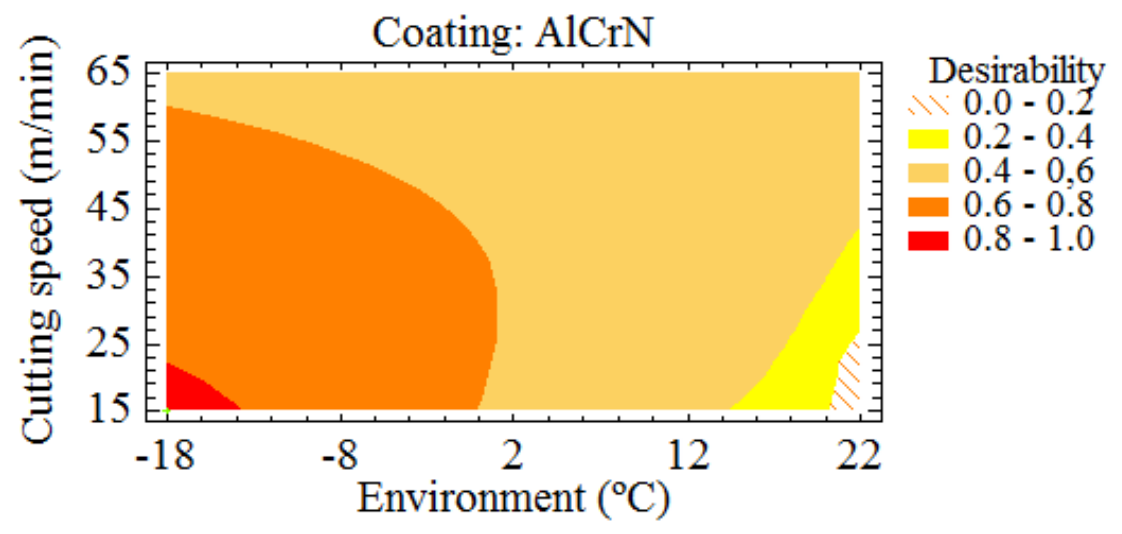

Figure 6. PA66-GF30: contours of the estimated response surface for the AlCrN coating.

\section{Conclusions}

A study based on machining through cooling air has been conducted, with the purpose of finding greener operation processes. These processes were performed on tapping operations in dry conditions and with two materials, PA66 and PA66-GF30. The experimental results were treated statistically by an ANOVA study, regression models, and multi-response optimization. In PA66, the environment is an influence factor, and the cooling of the tool affects the results of $F, T$, and $P$. Similar considerations can be realized for PA66-GF30, due to the influence of the first-order, second-order, or interaction effect of the "environment" factor.

A multi-response surface optimization shows that the optimum value can be found in environments close to $3{ }^{\circ} \mathrm{C}$ for PA66, while the optimum for PA66-GF30 is found at the minimal temperature studied $\left(-18^{\circ} \mathrm{C}\right)$. Thus, cooling air can be considered an adequate procedure for tapping operations to increase the sustainability of the manufacturing processes.

In future work, the influence of other geometries and the coating should be explored with regards to tapping operations in polyamide and reinforced polyamide, along with the effect of lower temperatures in the machining, particularly with PA66-GF30. In both materials, it can be of interest to seek other conditions that achieve a desirable result.

Acknowledgments: The authors thank the Spanish Ministry of Economy and Competitiveness for funding received through the DPI2011-27135 and DPI2014-58007-R projects, and the College of Industrial Engineers of UNED for their support through the 2017-IFC09 project.

Author Contributions: Rosario Domingo conceived and designed the experiments; Beatriz de Agustina y Marta M. Marín performed the experiments; Rosario Domingo, Beatriz de Agustina and Marta M. Marín analyzed the data; Beatriz de Agustina y Marta M. Marín contributed materials/analysis tools; Rosario Domingo wrote the paper. 
Conflicts of Interest: The authors declare no conflict of interest. The founding sponsors had no role in the design of the study; in the collection, analyses, or interpretation of data; in the writing of the manuscript; or in the decision to publish the results.

\section{References}

1. Modica, F.; Marrocco, V.; Copani, G.; Fassi, I. Sustainable micro-manufacturing of micro-components via micro electrical discharge machining. Sustainability 2011, 3, 2456-2469. [CrossRef]

2. Huang, J.; Jin, L.; Zhang, C. Mathematical modeling and a hybrid NSGA-II algorithm for process planning problem considering machining cost and carbon emission. Sustainability 2017, 9, 1769. [CrossRef]

3. Shokrani, A.; Dhokia, V.; Newman, S.T. Environmentally conscious machining of difficult-to-machine materials with regard to cutting fluids. Int. J. Mach. Tools Manuf. 2012, 57, 83-101. [CrossRef]

4. Boswell, B. Use of Air Cooling and Its Effectiveness in Dry Machining Processes. Ph.D. Thesis, Department of Mechanical Engineering, Curtin University of Technology, Bentley, Perth, Australia, 2008.

5. Nor-Khairusshima, M.K.; Che-Hassan, C.H.; Jaharah, A.G.; Amin, A.K.M.; Md-Idriss, A.N. Effect of chilled air on tool wear and workpiece quality during milling of carbon fibre-reinforced plastic. Wear 2013, 302, 1113-1123. [CrossRef]

6. Lee, P.H.; Lee, S.W. Experimental characterization of micro-grinding process using compressed chilly air. Int. J. Mach. Tools Manuf. 2011, 51, 201-209. [CrossRef]

7. Su, Y.; He, N.; Li, L.; Iqbal, A.; Xiao, M.H.; Xu, S.; Qiu, B.G. Refrigerated cooling air cutting of difficult-to-cut materials. Int. J. Mach. Tools Manuf. 2007, 47, 927-933. [CrossRef]

8. Liu, J.; Chou, Y.K. On temperatures and tool wear in machining hypereutectic Al-Si alloys with vortex-tube cooling. Int. J. Mach. Tools Manuf. 2007, 47, 635-645. [CrossRef]

9. Yuan, S.M.; Yan, L.T.; Liu, W.D.; Liu, Q. Effects of cooling air temperature on cryogenic machining of Ti-6Al-4V alloy. J. Mater. Process. Technol. 2011, 211, 356-362. [CrossRef]

10. Sun, S.; Brandt, M.; Dargusch, M.S. Machining Ti-6Al-4V alloy with cryogenic compressed air cooling. Int. J. Mach. Tools Manuf. 2010, 50, 933-942. [CrossRef]

11. Álvarez, R.; Domingo, R.; Sebastián, M.A. The formation of saw toothed chip in a titanium alloy: Influence of constitutive models. Strojniški Vestnik J. Mech. E. 2011, 57, 739-749. [CrossRef]

12. Domingo, R.; García, M.; Gómez, M.R. Determination of energy during the dry drilling of PEEK GF30 considering the effect of torque. Procedia Eng. 2013, 63, 687-693. [CrossRef]

13. Domingo, R.; Marín, M.M.; Claver, J.; Calvo, R. Selection of cutting inserts in dry machining for reducing energy consumption and $\mathrm{CO}_{2}$ emissions. Energies 2015, 18, 13081-13095. [CrossRef]

14. Kalpakjian, S.; Schmid, S.R. Manufacturing Engineering and Technology, 7th ed.; Pearson Education: Singapore, 2013.

15. Tsai, S.B.; Xue, Y.Z.; Huang, P.Y.; Zhou, J.; Li, G.D.; Guo, W.F.; Lau, H.; Shang, Z.W. Establishing a criteria system for green production. Proc. Inst. Mech. Eng. B J. Eng. Manuf. 2015, 229, 1395-1406. [CrossRef]

16. Nur, D.R.; Noordin, M.Y.; Izman, S.; Kurniawan, D. Machining parameters effect in dry turning of AISI 316L stainless steel using coated carbide tools. Proc. Inst. Mech. Eng. E J. Proc. Mech. Eng. 2017, 231, 676-683. [CrossRef]

17. Nur, R.; Kurniawan, D.; Noordin, M.Y.; Izman, S. Optimizing power consumption for sustainable dry turning of treated aluminum alloy. Procedia Manuf. 2015, 2, 558-562. [CrossRef]

18. Uzun, G.; Korkut, I. The effect of cryogenic treatment on tapping. Int. J. Adv. Manuf. Technol. 2013, 67, 857-864. [CrossRef]

19. Cao, T.; Sutherland, J.W. Investigation of thread tapping load characteristics through mechanistics modeling and experimentation. Int. J. Mach. Tools Manuf. 2002, 42, 1527-1538. [CrossRef]

20. Pereira, I.C.; Bacci da Silva, M.; Fernandes da Cunha, D.; Falco Sales, W. Analysis of tapping process in three types of cast iron. Int. J. Adv. Manuf. Technol. 2016, 82, 1041-1048. [CrossRef]

21. Domingo, R.; García, M.; Sánchez, A.; Gómez, R. A sustainable evaluation of drilling parameters for PEEK-GF30. Materials 2013, 6, 5907-5922. [CrossRef] [PubMed]

22. Davim, J.P.; Silva, L.R.; Festas, A.; Abrão, A.M. Machinability study on precision turning of PA66 polyamide with and without glass fiber reinforcing. Mater. Des. 2009, 30, 228-234. [CrossRef] 
23. Campos-Rubio, J.C.; da Silva, L.J.; de Oliveira-Leite, W.; Hallak-Panzera, T.; Ribeiro-Filho, S.L.M.; Davim, J.P. Investigations on the drilling process of unreinforced and reinforced polyamides using Taguchi method. Compos. Part B Eng. 2013, 55, 338-344. [CrossRef]

24. Quadrini, F.; Squeo, E.A.; Tagliaferri, V. Machining of glass fiber reinforced polyamide. Express Polym. Lett. 2007, 1, 810-816. [CrossRef]

25. Domingo, R.; García, M.; Gómez, R. Analysis of Energy Required During the Dry Drilling of High Performance of Polyamide PA 66 GF30. In Proceedings of the 17th International Congress on Project Management and Engineering, Logroño, Spain, 17-19 July 2013.

26. Armarego, E.J.A.; Chen, M.N.P. Predictive cutting models for the forces and torque in machine tapping with straight flute taps. CIRP Ann. Manuf. Technol. 2002, 51, 75-78. [CrossRef]

27. Domingo, R.; Calvo, R.; Marín, M.M.; de Agustina, B. Influence of tool cooling on thrust forces in tapping operations of reinforced polyamide. Procedia Manuf. 2017, 13, 343-347. [CrossRef]

28. Chim, Y.C.; Ding, X.Z.; Zeng, X.T.; Zhang, S. Oxidation resistance of TiN, CrN, TiAlN and CrAlN coatings deposited by lateral rotating cathode arc. Thin Solid Films 2009, 517, 4845-4849. [CrossRef]

29. Liew, W.Y.H.; Dayou, S.; Ismail, M.A.B.; Siambun, N.J.; Dayou, J. Dry sliding behaviour of AlCrN and TiN coatings. Adv. Mater. Res. 2012, 576, 559-564. [CrossRef]

30. Kutner, M.H.; Natchtsheim, C.J.; Neter, J.; Li, W. Applied Linear Statistical Models, 5th ed.; McGraw-Hill Irwin: New York, NY, USA, 2005.

31. Montgomery, D.C. Design and Analysis of Experiments, 8th ed.; John Wiley \& Sons Inc.: New York, NY, USA, 2012.

32. Derringer, G.; Suich, R. Simultaneous optimization of several response variables. J. Qual. Technol. 1980, 12, 214-219. [CrossRef]

33. Benyounis, K.Y.; Olabi, A.G.; Hashm, M.S.J. Multi-response optimization of $\mathrm{CO}_{2}$ laser-welding process of austenitic stainless steel. Opt. Laser Technol. 2008, 40, 76-87. [CrossRef]

34. Mia, M. Multi-response optimization of end milling parameters under through-tool cryogenic cooling condition. Measurement 2017, 111, 134-145. [CrossRef]

35. Benyounis, K.Y.; Olabi, A.G. Optimization of different welding processes using statistical and numerical approaches-A reference guide. Adv. Eng. Softw. 2008, 39, 483-496. [CrossRef]

36. Ekici, E.; Motorcu, A.R.; Uzun, G. An investigation of the effects of cutting parameters and graphite reinforcement on quality characteristics during the drilling of $\mathrm{Al} / 10 \mathrm{~B} 4 \mathrm{C}$ composites. Measurement 2017, 95, 395-404. [CrossRef]

37. Kumar, T.S.; Prabu, S.B.; Manivasagam, G.; Padmanabhan, K.A. Comparison of TiAlN, AlCrN, and AlCrN/ TiAlN coatings for cutting-tool applications. Int. J. Miner. Metall. Mater. 2014, 21, 796-805. [CrossRef] 